\title{
Future Trends in Endodontics: From the Virtual Assessment of the Anatomy to the Computer-driven Approach
}

\author{
Gianluca Gambarini ${ }^{1}$, Marco Seracchiani ${ }^{2}$, Maurilio D’Angelo ${ }^{3}$, Rodolfo Reda ${ }^{4}$, Luca Testarelli ${ }^{5}$
}

The Journal of Contemporary Dental Practice (2020): 10.5005/jp-journals-10024-2764

Root canal treatment is one of the most challenging practices in dentistry as the complexity and the variability of the endodontic space can often lead the operator to create false trajectories or missing canals. The technical advances in the development of even more efficient and resistant endodontic instrument reached important results in the last few years with the adoption of $\mathrm{NiTi}$ alloys and thermal treatments, which could increase the flexibility and the resistance of the instruments. ${ }^{1,2}$

However, to reach the success in endodontics, a correct diagnosis and the preliminary knowledge of the endodontic complex anatomy are mandatory for a successful root canal treatment. The gold standard in endodontics for the radiographic assessment of the tooth anatomy is still the periapical radiograph, but it can be often unable to visualize secondary or accessory canals, especially when positioned in the same root.,

Operatory microscopes are useful to find small orifices or to detect and retrieve broken instruments, but they are difficult to approach and are usually not present in every dental office. Furthermore, microscopes can enhance visualization, but their task is limited to the superficial areas of the access cavity: they cannot provide any clues about the more apical structures such as restrictions, lateral canals, curvatures, or calcifications. ${ }^{5}$

Since three-dimensional assessment of root canal anatomy has been introduced in the field of endodontics, clinical approach became more predictable due to the possibility of preventing accidents and complications caused by hidden canals or other peculiar characteristics of the endodontic complex. ${ }^{6}$

Cone-beam computed tomography (CT) resulted in a minor emission of ionizing radiations when compared with the most common CT-dentascan, and its emitted dose is quite similar to those produced by common film-based panoramic appliances. Actually, the only radiation-free device to obtain three-dimensional assessment of anatomical structures is the nuclear magnetic resonance, but nowadays its use in endodontics is still under evaluation; despite this it is considered a promising implement. ${ }^{7}$

Virtual analysis of the root canal complex can predict the presence of particularly difficult anatomies and reveal a higher possibility of missing treatment. The chance to know in advance the anatomical complexities can help the operator in the preliminary selection of the best approach for the clinical case, reducing the risk of failure.

In the very last few years, CT has been used to develop threedimensional dams to facilitate the clinical procedures by guiding the operator through hidden spaces, like the bone during the insertion of dental implants: ${ }^{8}$ the same technology seemed to be a promising tool even in surgical and nonsurgical endodontics. The possibility of reaching canals without opening an invasive cavity access through the guidance of a controlling device can help in
${ }^{1-5}$ Department of Oral and Maxillofacial Sciences, Sapienza University of Rome, Rome, Italy

Corresponding Author: Luca Testarelli, Department of Oral and Maxillofacial Sciences, Sapienza University of Rome, Rome, Italy, Phone: +39 3381504134, e-mail: luca.testarelli@uniroma1.it

How to cite this article: Gambarini G, Seracchiani M, D'Angelo $M$, et al. Future Trends in Endodontics: From the Virtual Assessment of the Anatomy to the Computer-driven Approach. J Contemp Dent Pract 2020;21(1):1.

Source of support: Nil

Conflict of interest: None

reducing the removal of sound dentine, preserving the tooth resistance. Device-controlled endodontic surgery has been shown to be less traumatic and can allow a better healing of the tissues due to a minimally invasive surgical access and minimal hard tissue removal while reaching a periapical lesion. ${ }^{9}$

\section{References}

1. Gambarini G, Miccoli G, Seracchiani M, et al. Fatigue resistance of new and used nickel-titanium rotary instruments: a comparative study. Clin Ter 2018;169(3):e96-e101. DOI: 10.7417/T.2018.2061.

2. Gambarini G, Piasecki L, Miccoli G, et al. Classification and cyclic fatigue evaluation of new kinematics for endodontic instruments. Aust Endod J 2019;45(2):154-162. DOI: 10.1111/aej.12294.

3. Gambarini G, Piasecki L, Ropini P, et al. Cone-beam computed tomographic analysis on root and canal morphology of mandibular first permanent molar among multiracial population in Western European population. Eur J Dent 2018;12(3):434-438. DOI: 10.4103/ ejd.ejd_116_18.

4. Viana Wanzeler AM, Montagner F, Vieira HT, et al. Can cone-beam computed tomography change endodontists' level of confidence in diagnosis and treatment planning? A before and after study. J Endod 2019; S0099-2399(19):30830-1. DOI: 10.1016/j.joen.2019.10.021.

5. Perrin P, Neuhaus KW, Lussi A. The impact of loupes and microscopes on vision in endodontics. Int Endod J 2014;47(5):425-429. DOI: 10.1111/ iej.12165.

6. Gambarini G, Piasecki L, Miccoli G, et al. Cone-beam computed tomography in the assessment of periapical lesions in endodontically treated teeth. Eur J Dent 2018;12(1):136-143. DOI: 10.4103/ejd. ejd_320_17.

7. Di Nardo D, Gambarini G, Capuani S, et al. Nuclear magnetic resonance imaging in endodontics: a review. J Endod 2018;44(4):536-542. DOI: 10.1016/j.joen.2018.01.001.

8. Mandelaris GA, Stefanelli LV, DeGroot BS. Dynamic navigation for surgical implant placement: overview of technology, key concepts, and a case report. Compend Contin Educ Dent 2018;39(9):614-621.

9. Gambarini G, Galli M, Stefanelli LV, et al. Endodontic microsurgery using dynamic navigation system: a case report. J Endod 2019;45(11):1397-1402. DOI: 10.1016/j.joen.2019.07.010. 